\title{
Supporting young people with dyslexia in international schools: a case study example of current provision in Southeast Asia
}

Julian Brown

Sheena Bell

\section{Key words}

inclusion, international schools, SEN, dyslexia

\begin{abstract}
This small-scale qualitative study examines professional and parental perspectives of dyslexia within international schools located in Bangkok. The views of participants indicated that there is a need for a greater awareness of 'dyslexia-friendly' approaches in these settings and a lack of resources to support the identification and teaching of individuals having specific needs. The findings also indicated that the collaboration between parents and professionals was central to what could be identified as 'good practice' and that the identification of difficulties alone without the acknowledgement of an individual's strengths could be detrimental. Opportunities for continuing professional development are highlighted as central to needs of professionals working within this region.
\end{abstract}

\section{Introduction}

This article focuses on a unique research project situated Bangkok and contributes to the understanding of the experiences of children with Special Educational Needs (SEN), specifically dyslexia, in international school settings. This study echoes a worldwide trend in which educational establishments expand as global business practices grow and gain international workforces. It is particularly relevant within a climate of 'Europeanization', as many of these establishments have European 
curricula and practices, to research inclusive educational cultures in international settings.

Over the last twenty to thirty years there has been a rapid expansion of international schools in Southeast Asia (Monthienvichienchai et al, 2002) which has coincided with a growing international labour market. Previous research has examined the globalisation of education (Mazzarol et al, 2003) and warned about the importance of taking into consideration the complexity of diverse cultural and social attitudes of the social context in which each school exists (Tate, 2012). Inevitably, international schools across the world will have culturally diverse environments that include children who grow up within multi-lingual environments. However, as we draw near to the twentieth anniversary of the Salamanca Statement (UNESCO, 1994), and attitudes to SEN and disability evolve, international schools, operating outside but alongside national systems, must adapt their practices to offer appropriate educational opportunities and support mechanisms for children who have additional needs such as dyslexia (Gabor, 2010). This coincides with a global movement towards inclusion in international settings causing changes and challenges for legislators and professionals (Forlin, 2010). Fee-paying international schools, many of which link to European educational systems, serve an itinerant professional labour-force for whom local schools are not deemed to be appropriate for language and/or cultural reasons. These schools also attract pupils from local populations catering for families who seek the prize of a bilingual education, often in English, and access to international universities. Despite many of these schools having some form of selection process, there seems to be a growing awareness of the importance of including children with diverse needs in the academic population of students.

The inclusion and support of young people with dyslexia in international school settings must be considered alongside the general attitudes 
towards SEN and the competitive nature of private sector schools. There are examples of research that has begun to examine some of the perceptions of SEN within Bangkok and reported a lack of clarity or common understanding of certain SEN concepts between cultures and languages (Grimes, 2012). Moreover, the fee-paying nature of international schools is likely to drive them to place a greater emphasis on competitiveness and academic standards, potentially to the detriment of identifying and supporting young people with individual needs. There are a number of potential limiting factors when considering children and young people (CYP) with dyslexia within any educational system. Firstly, it is questionable how widely applied the international definition of dyslexia (IDA, 2004) is within these contexts. It is also worth noting that the identification of disabilities such as dyslexia is resource-dependent and regions without appropriate specialist professionals or the potential to train practitioners already working in the context could limit possibilities of identifying difficulties or supporting teachers and schools in developing inclusive practices. Finally, dyslexia sits within a wider conceptualisation of SEN which may be influenced by socio-economic or cultural factors.

Research has also begun to examine and question whether practices and changes within education establishments has been commensurate to the intended changes promoted within legislation in some parts of Southeast Asia (Hallinger and Lee, 2011). Furthermore, it has been questionable whether the legislation which exists for those that are school age transfers into mechanisms which support the transition of young people with SEN into the workforce (Abdullah et al, 2011). Therefore, it is important to examine how dyslexia may be identified within the international school context, how attitudes towards and perceptions of special educational needs such as dyslexia manifest themselves globally and what the implications are for professionals or support staff (Tarry, 2011) who may be working in international schools with pupils having these needs. 


\section{Methods}

This research took place in Bangkok and was conducted over two visits by researchers in the context of an on-going, collaborative teaching project. A case study was selected as the most appropriate methodological approach, as the purpose of the research was to analyse one particular setting whilst recognising its complexity and context (Punch, 2009); particularly true of cities across Southeast Asia.

One international centre specializing in SEN was selected as the focus of the study as it provides a support and assessment role for other international schools in the city and other parts of Southeast Asia (working with approximately 250 pupils across the region). Further data were collected which extended the study to a range on international schools in the city, all of whom have links to the centre through students with SEN.

When deciding on a purposive sample of participants for the case study it was deemed essential to gain multiple perspectives of the same concept. Therefore research has been conducted with both professionals and nonprofessionals, enabling the researchers to gain a more rounded perspective of the attitudes represented in the wider cultural context. The researchers also considered this essential as they sought to examine dyslexia within an ecological perspective of disability (Bronfenbrenner, 1979).

The first phase of the research included a questionnaire that the researchers sent electronically to teachers and support staff who they would be working with prior to visiting the city. Following this a purposive sample was gathered by the researchers which included four participants from one special educational needs centre and three teaching/support staff from three other international school settings. A preliminary interview to elicit background and contextual data was conducted with the 
founder/head teacher of the special needs centre by both researchers during an initial ten-day stay in the city. The second phase of semistructured interviews (two with parents, one with a pupil and three with teaching/support staff) were conducted five months later by one of the researchers during a second stay of six days. The interviews were recorded and transcribed. Interviews were then coded and cross coded by both researchers to reach internal validation. The subsequent section uses a series of illustrative extracts that highlight the key issues identified.

\section{Origins of the centre}

The centre that forms the focus of the study began over fourteen years ago and was established by a Special Educational Needs Coordinator (SENCo) who had previously taught in the UK and then at an international school. It was formed due to a need identified by the then SENCo as there was 'very little support for international schools generally' in the city. He noticed there were children with SEN who were not receiving adequate provision or their needs being appropriately identified. The school began with one child who had ended up being asked to leave another large international school. After a period of months in which the SENCo worked individually with this child he was reintegrated back into a larger international school.

A significant factor when examining the origins of the centre was that the founder had had very negative experiences when he was in school. He recounted his time when he attended a large English secondary school where he spent most of his time in a 'special needs hut'. He emphasised that, 'school really, if anything, was just reinforcing you're a failure. I worked very hard to avoid classes or the work.' It is well documented that self-esteem and perceived low expectations can impact all learners, and especially those with dyslexia (Gibson \& Kendall, 2010; Burden, 2005). 
Importantly, there was a factor that changed his life, a teacher, who gave him the self-belief that now he hopes to pass on to other children. 'I was very lucky to have a good teacher who recognized we had some strengths and was willing to work with us, and without her, I wouldn't be doing what I am doing now.' This was an important turning point and helped to shape his ideas around the learning centre he has established.

\section{Collaboration, competencies and skills of professionals}

The centre's network of support for dyslexia relates to an understanding of multi-agency work which maps broadly to an ecological model of special educational needs (SEN) and dyslexia support (Bronfenbrenner 1979; Poole 2003). When a student begins at the centre, a 'case conference' is held that establishes a baseline of understanding around the young person's strengths and areas for development. This involves all the professionals who are located within the centre, family members, teachers and support staff. The centre benefits from having a wide range of professionals working directly with the young people including a speech and language therapist, physiotherapist, counsellors and specialist teachers. A parent commented how this helped her to have all the professionals involved, 'At this particular place you've got all those things and it's a programme set up for individual children,' whilst she recognised this was a unique provision as 'some of the schools haven't got speech therapy' (Parent 1). Once educational targets and strategies are established these are disseminated to an additional layer of support that the young person may come across including drivers, cooks, cleaners and administrative staff. This model of identification and support has evolved due to a lack of any professional services within the city for the centre to access.

The professionals interviewed shared concerns about the lack of expertise in certain areas of SEN and that this provided a challenge for international schools, 'I would say one of the hardest things in South East Asia is there 
are no assessors. ... There is only maybe one assessor for all of Southeast Asia and he just does an assessment and doesn't give recommendations for teaching strategies afterwards' (Professional 1). This can be compounded by the temporary nature of some international contracts, 'this is one of the things I would say is an on-going issue with an ex-pat community' (Professional 2). This is something which one parent commented from their perspective that the case study centre had managed successfully, 'of course there's situations of people coming and going, of course some people stay only one year. Whenever there came replacements of the new guys... they were great replacements of the great ones who left' (Parent 2). So, although individual staff in international settings may move on relatively rapidly, they may be replaced with others who are perceived to be of equal quality. However, this undoubtedly poses challenges for leaders in international schools that may be distinct from other educational establishments.

The availability of good quality SEN training for staff in international settings was also shown to be of concern. Professionals noted there may be misconceptions amongst staff, especially in the area of dyslexia to explain, 'what it is, what it looks like, how you teach somebody with it. There's a belief that it exists (dyslexia) but the understanding of it isn't there, even within the teaching staff the understanding isn't there' (Professional 2). This raises important questions about what professional development is required as international educational contexts become more diverse. This correlates to findings within the OECD that stated the most significant amount of development teachers requested internationally was in the area of SEN (Schleicher, 2012). The head of the centre commented that this was a challenge within the region: 'trying to keep up with current thinking and developments, being out in Asia, it's hard.' Research has shown that training and professional development for teachers is important to provide skilled dyslexia support (Bell, 2013). A 
main obstacle that the centre tries to overcome is keeping the professionals at the centre having up-to-date knowledge and skills.

\section{Partnerships with parents}

The case conferences have acted as important collaborative processes with the parents, an area for school development re-examined regularly within the English educational system (Lamb, 2009). One parent commented that the case conferences had enabled her to feel as though she was working in partnership with the school and that their views were an important part of the collaborative support: 'Here the parent can walk through the door. You feel involved as a parent and it doesn't matter if you come in during lesson time you can still ask questions' (Parent 1). Another parent appreciated the 'target agreements' that were formed from the case conferences. Most importantly the 'target agreement' was a mutually agreeable document that the parent was consulted about. He commented that, 'They even do things like target agreements which I only knew of from professional work in the past. So I do target agreements with my boss and with my team. So here I got at the beginning of the year I get a target agreement from the teacher. We discuss it, 'are you happy with those targets'. I was more than happy with these targets which they worked out for my son' (Parent 2).

The head of the centre stresses that they would prioritise the views and experiences of the young person and their family to promote understanding of their perspectives, which are vital to establish a successful educational partnership. A large network of professionals, employed by the school, is then drawn upon to aid the young person's development. This network, being based in school, provides a comprehensive and collaborative approach to assessing and supporting the young person. Whilst this is recognised as an important aspect of dyslexia support in English school settings, it may be particularly 
important when families are away from their home country and extended family or community support.

\section{'It's just someone else in your class, it's not a big deal' (Professional 1): Contextual challenges to inclusive culture?}

As the professional quoted above articulated, inclusive practice can be seen a part of the normal philosophy and beliefs of professional teachers in this unique trans-national setting. However, attitudes towards inclusion and diversity clearly vary amongst all international contexts. Rose et al (2013) warn that:
'Attempts to transport a westernised approach to education to cultural contexts which differ greatly from those in which inclusive schooling has been advanced. The potential for cultural dislocation is clearly in evidence and may prove to be an inhibiting factor rather than a means of promoting the inclusion agenda.' (Rose et al, 2013, p.1)

Due to the small size of this study, generalisations about attitudes cannot be made. However, it was noted within all the interviews with professionals and parents that there were particular contextual attitudes to SEN that may provide an additional barrier to individuals and educational establishments alongside an inevitable tension between academic standards and inclusion.

One potential such barrier to inclusion is the imperative of meeting the achievement agenda for schools. International schools work in a competitive market in which exam results and university admissions are highly valued. In terms of accepting children with an identified SEN, this can lead to schools rejected potential candidates who may not achieve high results in testing:

'They don't want to advertise it... "We don't want to get lots of them.. [children with SEN].. how would that look on our grades?".... That's how I feel it is.' (Professional 1) 
There does not appear to be any legislative imperative or protocol for such schools to accept students with disabilities. Parents in this study reported difficulties in finding a place for their child in local international schools:

'We went to another school and we met the headmistress at the time and the first thing she said to me was, "No we don't want him. He'll keep our numbers down"... We were told by two schools that he wasn't up to their standard. So we agreed for him to come here.' (Parent 1)

There was also evidence of exclusions from schools because of SEN, which is particularly of concern in a context where no other local possibilities might be available to a 'non-native' learner:

'We just had an example from one school with friends of us. I will not say the name of the school, but there is a kid with a syndrome and they asked the parents to take the kid out.' (Parent 2).

Parents also expressed concerns about schools which advertised support which did not seem to be effectively put into practice:

'They all have such a programme. Saying we do this and that. But if you look behind the curtain, there's not much, or not much that I have seen.' (Parent 2)

Another potential threat to inclusive practice is the influence of local culture. The make-up of an international school pupil population is not all from an expatriate community, with many local parents sending their children to international schools seeking a bi- or multi-lingual education. In this part of Southeast Asia, there may be a resistance to a Western or Europeanized attitude identification of SEN or inclusive teaching practices. The following professionals found communicating with parents about SEN challenging:

Culturally they don't wasn't to lose face. Culturally it doesn't exist and its bad karma coming back to you and your family. (Professional 1)

Some families really can't accept it and some might just go to another school. (Professional 3) 
It is very important that any training or development work in international settings should take into consideration and be sensitive to long held values and beliefs (Grimes, 2013; Rose et al, 2013).

\section{Change and progression}

The challenges mentioned in the previous section are not unique or only applicable to international educational settings. Indeed they can manifest themselves in any organisation which is dependent upon individuals' perceptions and attitudes. However, they could be exacerbated within an international school, which is fee-paying and therefore may be more conscious of these issues. These were highlighted by the head of centre as aspects that he had experienced and had become a challenge for any professional in the region supporting the inclusion of young people with dyslexia.

'The other difficulty we have is the cultural aspect of being in a country where it's (dyslexia) not recognised yet to the level it is in other parts of the world and there's not the legislative support. It's not a criticism. It's just where we find ourselves at this moment in time. My frustrations are more realisations that this is where we're at and we'd all want to be further on than we really are. Accepting this is going to be in small steps and I can see that' (Head of Centre).

As attitudes towards inclusion change so may potential implications for the centre as well as the international school population. He suggests that, 'some of the children that are coming to us could be supported in international school settings. Ideally that's what we'd like to see.' These issues are important considerations as the international community considers how far the Salamanca Agreement (UNESCO, 1994) has come to fruition, and begs the question as to whether international schools, which, with their particular international, rather than country based, status, are working towards inclusive educational practices.

\section{Examples of 'good practice' identified in the Centre}


'Good practice' when supporting learners with dyslexia can denote many things: multisensory teaching, supporting self-esteem, robust assessment. These are applicable to the case study centre. Increasingly there is an emphasis on personalised approaches to learning and focusing on the strengths of the individual. All professionals are also encouraged to emphasise the things the young person is good at as, 'there is a knock on effect if you work with the strengths of that child' according to the head of the centre. This pedagogical method lies at the heart of his educational philosophy and is based on his own educational experiences:

'The one thing I would want them to realize if they had SPLD is that they are good at something. That literacy and numeracy, those two areas they may be having difficulty in, are not criteria for success out there. It may be in the schools, but not out there. And if they can realise that and not have to worry about that once they leave the school setting, then they will be fine' (Head of Centre).

Additionally there were other aspects that the data suggested were specific to this particular context. One aspect appreciated by both parents and the young person included the emphasis on the individual and their particular interests,

'The school looked at the individual person. It's not like you are this age and you should be doing this it's what can we do for you' (Parent 1).

This was echoed by the student,

'Everyone's got time for every child and they all understand their needs and they cater for them. And I think that they don't ask them what they can't do and they set their work to what's to their level' (Student 1).

\section{Conclusion}

There are lessons to be learnt from the examination of this case study. Through the implementation of multi-agency working, even in an international school setting it is possible to form a holistic and comprehensive support network in supporting a child or young person and that includes the family at the heart of any such network. Although this 
approach will always be determined by the resources that are accessible, one can see the benefits of working collaboratively in such a 'joined up' way. International schools, and increasingly schools in England, face particular challenges in addressing cross-national language differences and cultural attitudes of families from diverse backgrounds which are likely to have a significant impact on the way CYP with dyslexia are supported.

It is worth reminding ourselves of the challenges individuals with dyslexia may experience to their self-esteem in their school career and that it can be the self-belief of one teacher or support worker who could make the difference to their life chances. For international schools this could be masked, when one considers the international comparisons of literacy and numeracy attainment as being measures of 'success'.

Training for teachers and other professionals in international settings is needed and there is a potential for trainers from western cultures to develop links, not only in international schools but through them towards working with local teachers in partnership (Rose et al, 2013), through an examination of CPD leading to an MA degree provided in India, suggest that 'the provision of high quality professional development is one important aspect of ensuring a transition towards a more inclusive school system' (p.9). This study, originally begun as an investigation into the development of an MA course in Bangkok, has echoed these findings. As Grimes has shown, 'The cultural world of school leaders and teachers needs to be taken into consideration when trying to understand the ways in which inclusive teacher development can be effectively supported' (Grimes, 2013, p.187). For students with dyslexia there is vast potential for support and intervention which can be translated into international and trans-national settings by working in close collaboration with teachers in the field. 
Finally, in a time of changing educational context and austerity in England, it is worth a constant re-examination of identification and support for learners with dyslexia and how dependent this can be on any resources available both internally and externally to schools.

Word count: 3828

\section{References}

Abdullah, M., Mey, S., Eng, T., Othman, R. and Omar, A. (2011) Schoolto-work transition services for students with disabilities in Malaysia: organisations' views on policy and practices. Journal of Research in Special Educational Needs, 2 (2), 1-13.

Bell, S. (2013) Professional development for specialist teachers and assessors of students with literacy difficulties/dyslexia: 'to learn how to assess and support children with dyslexia'. Journal of Research in Special Educational Needs, 13(1), 104-113.

Bronfenbrenner, U. (1979) The Ecology of Human Development. Cambridge, Mass: Harvard University Press.

Burden, R. (2005). Dyslexia and self-concept: seeking a dyslexic identity. London: Whurr.

Forlin, C. (2010) The role of the school psychologist in inclusive education for ensuring quality learning outcomes for all learners. School Psychology International, 31 (6), 617-630.

Gabor, G. (2010) Can students with dyslexia be effectively supported in the diversity of an international school setting. Journal of Research in Special Educational Needs, 10 (1), 31-41.

Gibson, S. and Kendall, L. (2010) Stories from school: dyslexia and learners' voices on factors impacting on achievement. Support for Learning, 25(4), 187-193. 
Grimes, P. (2013) Considering the continuing development of inclusive teachers: a case study from Bangkok, Thailand. European Journal of Special Needs Education, 28(2), 187-202.

Hallinger, P. and Lee, M. (2011) A decade of educational reform in Thailand: broken promise or impossible dream? Cambridge Journal of Education, 41 (2), 139-158.

International Dyslexia Association (2013) [Online] Available http://www.interdys.org/FAQ.htm [Accessed 10 June 2013]

Lamb, B. (2009) Report to the Secretary of State on the Lamb inquiry review of SEN and disability information. London: DCSF.

Mazzarol, T., Soutar, G., Norman, M. and Sim Yaw Seng (2003) The third wave: future trends in international education, The International Journal of Education Management, 17 (2), 90-99.

Monthienvichienchai, C., Bhibulbhanuwat, S., Kamsemsuk, C. and Speece, M. (2002) Cultural awareness, communication apprehension, and communication competence: A case study of Saint John's International School. The International Journal of Educational Management, 16 (6), 288-296.

Poole, J. (2003) Dyslexia: A wider view: the contribution of an ecological paradigm to current issues. Educational Research, 45(2), 167-180.

Punch, K. (2009) Introduction to Research Methods in Education. London: SAGE.

Rose, R., Doveston, M., Rajanahally, J., Jament, J. and Visser, J., (2013) Supporting inclusive classroom: can Western approaches to teaching be applied in an Indian context. AFID 2013 - 21st Conference of the Asian Federation on Intellectual Disabilities, 7 - 11 October 20132013. 
Schleicher, A. (2012) Ed. Preparing Teachers and Developing School Leaders for the $21^{\text {st }}$ Century: Lessons from around the World. OECD Publishing.

Tarry, E. (2011) British international schools: the deployment and training of teaching assistants. Journal of Research in International Education, 10 (3) 293-302.

Tate, N. (2012) Challenges and pitfalls facing international education in a post-international world. Journal of Research in International Education, 11 (3) 205-217.

UNESCO (1994) The Salamanca statement on principles, policy and practice in special needs education. Spain: UNESCO World conference on Special Needs Education. 